\title{
Üst gastrointestinal sistem lipomları: 33 olgunun irdelenmesi
}

\author{
Upper gastrointestinal lipomas: Analysis of 33 patients \\ Ahmet AYDIN, Fatih TEKIN, Murat AKYILDIZ, Ömer ÖZÜTEMIZ \\ Ege Üniversitesi Tıp Fakültesi, Gastroenteroloji Bilim Dalı, Izmir
}

\begin{abstract}
Giriş ve Amaç: Bu çalışmanın amacı, kliniğimizde lipom tanısı alan olgularımızın özelliklerini değerlendirmektir. Gereç ve Yöntem: Kliniğimizde Temmuz 2000-Subat 2009 tarihleri arasinda endoskopik ultrasonografi ile lipom tanısı alan 33 olgunun dosyaları retrospektif olarak irdelenmiştir. Bulgular: Onaltısı erkek $(\% 48,5), 17$ 'si $(\% 51,5)$ kadın olan olgularnn yas ortalaması 54 (33-85) idi. En slk endoskopi endikasyonu dispepsi idi. Tüm hastalar endoskopik ultrasonografideki tipik özellikler ile lipom tanısı aldı. Lezyonlar en sık olarak antrumda saptandı. Sonuç: Lipomların tanısında, tanı koydurucu tipik bulguların varlığ nedeniyle endoskopik ultrasonografi ilk tercih edilmesi gereken tanı yöntemidir.
\end{abstract}

Anahtar Kelimeler: Üst gastrointestinal sistem, lipom, endoskopik ultrasonografi

\section{GİRISS}

Lipomlar yağ dokusunun benign tümörleridir. Gastrointestinal sistemin heryerinde görülebilirler; ancak en sık kolon ve ince barsaklarda bulunurlar. Genellikle semptoma yol açmayan bu lezyonlar başka nedenlerle yapılan üst gastrointestinal sistem endoskopileri sırasında rastlantısal olarak görülürler. Bazı olgularda karın ağrısı, kanama ve obstrüksiyon bulguları görülebilir. Bu çalışmanın amacı, kliniğimizde endoskopik ultrasonografi ile lipom tanısı alan olgularımızın irdelenmesidir.

\section{GEREC VE YÖNTEM}

Kliniğimizde Temmuz 2000-Şubat 2009 tarihleri arasında endoskopik ultrasonografi ile lipom tanısı alan 33 olgunun dosyaları retrospektif olarak incelenmiştir. Olguların demografik özelliklerine ek olarak endoskopi yapılma nedenleri, lezyonların endosonografi özellikleri, lokalizasyonları, sayısı ve boyutları irdelenmiştir.

\section{BULGULAR}

Toplam 33 olgunun 16'si $(\% 48,5)$ erkek, 17'si $(\% 51,5)$ kadın

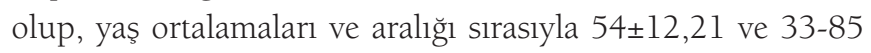
yll olduğu görülmüştür. Endoskopide tanımlanan tüm submukozal lezyonların normal mukoza ile örtülü olduğu görülmüş, endosonografide ise tüm lezyonların 3. sonografik taba-
Background and Aims: The aim of this study was to evaluate the characteristics of patients diagnosed as lipoma. Materials and Methods: Patients diagnosed as lipoma in our department between July 2000-February 2009 were analyzed. Results: There were 16 (48.5\%) male and 17 (51.5\%) female patients, with an average age of 54 (33-85). Dyspepsia was the most common indication for endoscopy. All of the patients were diagnosed based on the typical endoscopic ultrasonographic findings of lipomas. The antrum was the most common localization for the lesions. Conclusions: Endoscopic ultrasonography is the first diagnostic tool for diagnosis of lipomas because of its typical endosonographic findings.

Key words: Upper gastrointestinal system, lipoma, endoscopic ultrasonography

kadan (submukozadan) kaynaklanan hiperekoik, homojen ve düzgün sınırlı lezyonlar şeklinde oldukları saptanmıştır (Resim 1, 2). Mukoza, muskularis propria ve seroza tabakaları

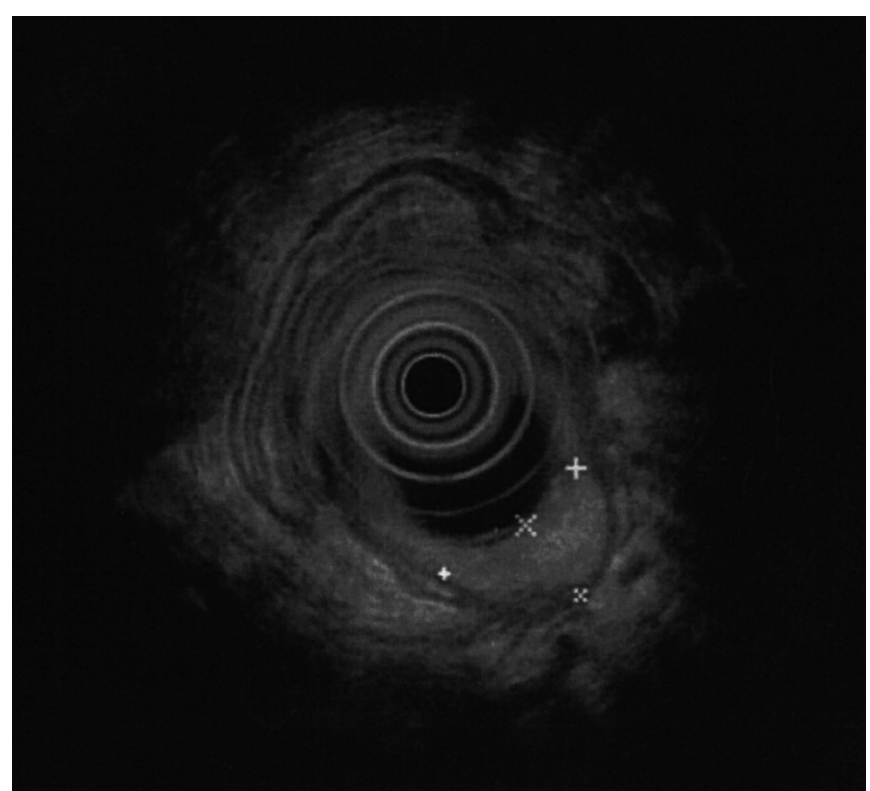

Resim 1. Duodenal bulbusta submukozal yerleşimli, 20x10 mm boyutlarında, düzgün kenarlı homojen hiperekoik kitle saptanmıştır. Kas tabakası ve seroza normal olarak değerlendirilmiş, lenfadenopati saptanmamıștır. 


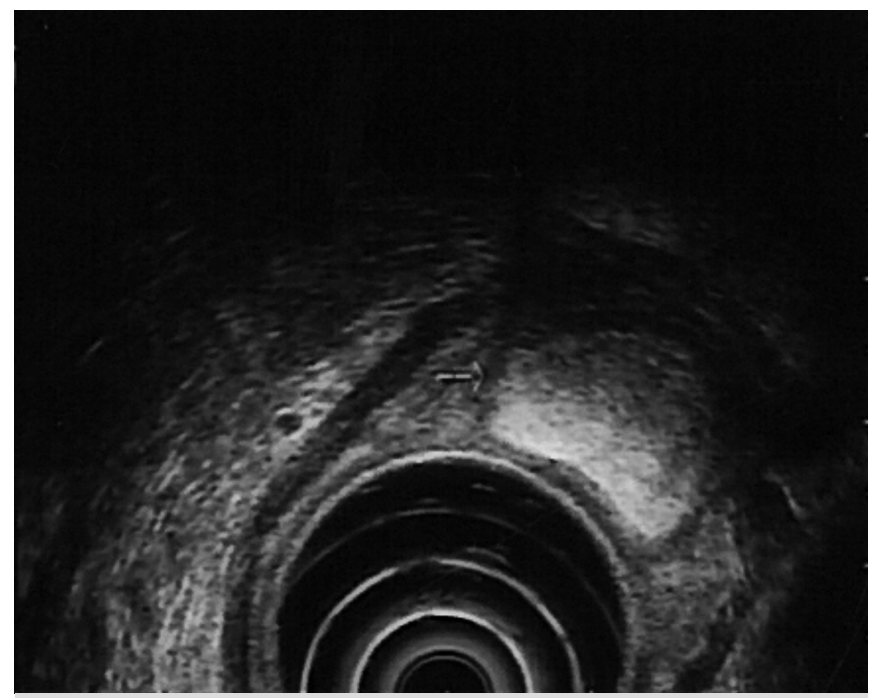

Resim 2. Antrumda lokalize lipomun endosonografik görüntüsü.

normal bulunmuş olup hiçbir olguda lenfadenomegali saptanmamıştır. En sık endoskopi endikasyonunun dispepsi olduğu ve lezyonların en sık olarak antrumda lokalize olduğu dikkati çekmiştir. Otuzüç olguda toplam 39 lipom görülmüş olup, olguların 4'ünde 2 adet, birinde de 3 adet lipom saptanmıştır. Olguların klinik özellikleri Tablo 1'de özetlenmiştir.

\section{TARTISQMA}

Yağ dokusunun benign tümörleri olan lipomlar gastrointestinal sistemin her yerinde görülebilirler. Siklıkla rastlantısal olarak tanı alırlar. Başka nedenlerle yapılan endoskopilerde sarımsı renkte, düzgün mukoza ile örtülü submukozal lezyonlar olarak görülürler. Alınan endoskopik biyopsiler tanı için yeterli değildir ve siklıkla normal mukoza olarak rapor edilirler. Endoskopi sırasında biyopsi pensi ile lezyona bastırıldığında, lezyonun yumuşak olduğu ve biyopsi pensi geri çekildiğinde de indentasyon bıraktığı görülür. Buna yastık belirtisi (pillow sign) adı verilir. Lipomlar çoğu zaman asemptomatik olsalar da, bazen karın ağrısı, obstrüksiyon, intususepsiyon ve gastrointestinal sistem kanamasına yol açabilirler (13). Her ne kadar benign lezyonlar olarak bilinseler de, literatürde liposarkom dönüşümleri ve kolon/mide adenokarsi- nomları ile birliktelikleri de tanımlanmıştır $(4,5)$.

Endoskopik ultrasonografik değerlendirmede lipomlar üçüncü sonografik tabakadan (submukozadan) köken alan hiperekoik ve homojen lezyonlar olarak görülürler (6). Tipik endoskopik ultrasonografik görüntüleri nedeniyle ince iğne aspirasyon biyopsisine gerek duyulmamaktadır.

Insidental olarak bulunan asemptomatik lipomlarda tedavi ya da takibe gerek yoktur. Semptomatik olanlarda cerrahi tedavi gereklidir. Literatürde lipomların başarılı bir şekilde endoskopik rezeksiyonu da tanımlanmıştır, ancak özellikle $2 \mathrm{~cm}$ ve daha büyük olanlarda bu işlemin perforasyon bakımından yüksek risk taşıdığı bildirilmiştir $(3,7)$.

Sonuç olarak lipomlar endoskopik olarak diğer submukozal tümörlerden tam olarak ayırt edilemezler ve endoskopik mukozal biyopsiler ile taniya gidilemez. Bu submukozal lezyonların tanısında, tanı koydurucu tipik bulguların varlığı nedeniyle endoskopik ultrasonografi ilk tercih edilmesi gereken yöntemdir.

\begin{tabular}{|c|c|}
\hline Parametre & Olgu sayısı ve yüzdesi (n, \%) \\
\hline \multicolumn{2}{|l|}{ Endoskopi nedenleri } \\
\hline Dispepsi & $24(\% 72,7)$ \\
\hline Üst GIS kanaması & $5(\% 15,2)$ \\
\hline Reflü yakınmaları & $2(\% 6,1)$ \\
\hline Akalazya & $1(\% 3)$ \\
\hline ERCP sirasinda tesadüfen & $1(\% 3)$ \\
\hline \multicolumn{2}{|l|}{ Lezyon sayısı } \\
\hline Tek lezyon & $28(\% 85)$ \\
\hline Iki lezyon & $4(\% 12)$ \\
\hline Üç lezyon & $1(\% 3)$ \\
\hline \multicolumn{2}{|l|}{ Lokalizasyon (lezyon sayısı=39) } \\
\hline Antrum & $19 / 39(\% 48,7)$ \\
\hline Korpus & $7 / 39(\% 18)$ \\
\hline Duodenum & $11 / 39(\% 28,2)$ \\
\hline Bulbus & $2 / 39(\% 5,1)$ \\
\hline 2. segment & $9 / 39(\% 23,1)$ \\
\hline Özofagus & $2 / 39(\% 5,1)$ \\
\hline En küçük çaplı lezyon & $4 \times 4 \mathrm{~mm}$ \\
\hline En büyük çaplı lezyon & $41 \times 30 \mathrm{~mm}$ \\
\hline
\end{tabular}

\section{KAYNAKLAR}

1. Yoshimura H, Murata K, Takase K, et al. A case of lipoma of the terminal ileum treated by endoscopic removal. Gastrointest Endosc 1997:46:461-3

2. Tatsuguchi A, Fukuda Y, Moriyama T, Yamanaka N. Lipomatosis of the small intestine and colon associated with intussusception in the ileocecal region. Gastrointest Endosc 1999;49:118-21.

3. Kim CY, Bandres D, Tio TL, et al. Endoscopic removal of large colonic lipomas. Gastrointest Endosc 2002;55:929-31.

4. Siegal A, Witz M. Gastrointestinal lipoma and malignancies. J Surg Oncol 1991;47:170-4.
5. Moreira LF, Iwagaki H, Matsumo T, et al. Submucosal lipomas synchronous with an early gastric cancer. J Clin Gastroenterol 1992;14:173-4.

6. Yasuda K, Nakajima M, Yoshida S, et al. The diagnosis of submucosal tumors of the stomach by endoscopic ultrasonography. Gastrointest Endosc 1989;35:10-5

7. Pfeil SA, Weaver MG, Abdul-Karim FW, Yang P. Colonic lipomas: outcome of endoscopic removal. Gastrointest Endosc 1990;36:435-8. 